\title{
Smectic structure and glass transition in poly(butylene terephthalate)
}

Polymer Journal (2010) 42, 349-353; doi:10.1038/pj.2010.5; published online 10 February 2010

\section{INTRODUCTION}

Poly(butylene terephthalate) (PBT) is a semicrystalline polyester that is used extensively in many engineering materials. PBT has two triclinic crystalline forms, the $\alpha$-form and the $\beta$-form, ${ }^{1-4}$ and a smectic liquid crystalline structure. $^{5}$ The $\alpha$-form is mainly obtained when PBT is crystallized from molten or glassy states. Recently, we investigated the crystallization of PBT from glass by smallangle X-ray scattering and differential scanning calorimetry (DSC), and revealed that PBT crystallizes through a mesomorphic phase, which has an intermediate structure between crystal and amorphous. ${ }^{6}$ The $\beta$-form is produced when the $\alpha$-form is held under strain, and then reversibly transforms to the $\alpha$-form on removal of the strain. The main difference between these forms is that the $c$ axis (fiber axis) length of the $\alpha$-crystalline unit cell $(\sim 11.6 \AA)$ is shorter than that of the $\beta$-form $(\sim 13.0 \AA)$. The conformations of the four methyl groups in the $\alpha$ - and $\beta$-forms are the gauche-trans-gauche and all-trans conformations, respectively. The smectic structure of PBT is obtained when amorphous PBT is stretched at room temperature and transforms into the $\alpha$-form with heating. ${ }^{5}$ The length of the smectic periodicity is $11.69 \AA$, which corresponds to the $c$ axis length of the $\alpha$-crystalline unit. ${ }^{5}$

Similar smectic ordering has been found in other polyesters ${ }^{7-10}$ and isotactic polypropylene (iPP). ${ }^{11-14}$ For poly(ethylene terephthalate $)^{7,8}$ and poly(ethylene naphthalate), ${ }^{9}$ smectic structures are formed only by stretching glassy state polymers. For poly(butylene naphthalate) $(\mathrm{PBN})^{10}$ and $\mathrm{iPP},{ }^{11-14}$ smectic structures are also formed by rapid quenching from the molten state without stretching. In the latter polymers, two glass transition temperatures $\left(T_{\mathrm{g}}\right)$ are observed; the $T_{\mathrm{g}}$ of the smectic structure, $T_{\mathrm{g}}^{\mathrm{sm}} 65^{\circ} \mathrm{C}$ for $\mathrm{PBN}$ and
$1{ }^{\circ} \mathrm{C}$ for iPP, is higher than the $T_{\mathrm{g}}$ of the isotropic amorphous liquid, $T_{\mathrm{g}}$ am $45^{\circ} \mathrm{C}$ for PBN and $-30{ }^{\circ} \mathrm{C}$ for iPP. ${ }^{10,12}$ Thus, $T_{\mathrm{g}}{ }^{\mathrm{sm}}$ is higher than $T_{\mathrm{g}}^{\mathrm{am}}$ for polymers forming the smectic structure by quenching or by stretching the glassy state. In PBT, the value of $T_{\mathrm{g}}$ has not been well established, because the crystallization rate of PBT is much higher than that of poly(ethylene terephthalate), and a complete amorphous state is not formed. Recently, Pyda et al. ${ }^{15,16}$ reported the $T_{\mathrm{g}}$ of PBT as $314 \mathrm{~K}$ from DSC results. The aim of this study is to clarify $T_{\mathrm{g}}$ for PBT, and discuss the relationship between the observed $T_{\mathrm{g}}$ and smectic structure formation of PBT.

\section{EXPERIMENTAL PROCEDURE}

PBT (viscosity average molecular weight $M_{\mathrm{v}}=38000$, Sigma-Aldrich Co. Ltd, St Louis, MO, USA) was used as the starting material. PBT was melted at $\sim 280^{\circ} \mathrm{C}$ for 2 min on a hot plate and then rapidly quenched in ice water. The thickness of the quenched PBT film was $\sim 150 \mu \mathrm{m}$. The quenched PBT was examined immediately after quenching by one-dimensional wideangle X-ray diffraction (1D-WAXD) at room temperature. Quenched PBT films that annealed at $40, \quad 60$ and $180^{\circ} \mathrm{C}$ for $30 \mathrm{~min}$ were also examined using 1D-WAXD. The quenched PBT films were uniaxially stretched to four times their length at room temperature. The stretched PBT films were annealed at 40,60 and $180^{\circ} \mathrm{C}$ for $30 \mathrm{~min}$, cooled to room temperature and then examined by two-dimensional WAXD (2DWAXD). WAXD measurements were performed using a Rigaku Rint 2500 system (Rigaku Corporation, Tokyo, Japan). WAXD patterns were recorded using an imaging plate that covers the $q$-range from 0.4 to $4 \AA^{-1}(q=4 \pi(\sin \theta) / \lambda$, where $\lambda$ and $2 \theta$ are the $\mathrm{X}$-ray wavelength and scattering angle, respectively). Before DSC measurements (Shimadzu DSC60 (Shimadzu Corporation, Kyoto, Japan), $10{ }^{\circ} \mathrm{C} \mathrm{min}^{-1}$, -100 to $250{ }^{\circ} \mathrm{C}$ ), the quenched PBT was uniaxially stretched to four times its length at $0{ }^{\circ} \mathrm{C}$ in ice water and at room temperature, and then annealed in the same way as for the WAXD measurements. The sample histories for DSC measurements are listed in Table 1.

\section{RESULTS AND DISCUSSION}

Structures of quenched PBT with and without stretching

Figures $1 \mathrm{a}-\mathrm{d}$ show WAXD patterns measured at room temperature for the PBT quenched from the melt to $0{ }^{\circ} \mathrm{C}$ and the quenched PBT films annealed at 40,60 and $180^{\circ} \mathrm{C}$ for $30 \mathrm{~min}$, respectively. The quenched PBT is identified as the amorphous phase, because of amorphous halo and the absence of crystalline peaks in the WAXD pattern. The $\alpha$-crystalline peaks at $q=0.64,1.15,1.22,1.46$, $1.65,1.77,2.05$ and $2.20 \AA^{-1}$ appear for the films annealed at $40{ }^{\circ} \mathrm{C}$ and above, and the intensities increase with increasing annealing temperature.

Figures 2a-d show 2D-WAXD images of the as-stretched PBT and the PBT stretched and annealed at 40,60 and $180^{\circ} \mathrm{C}$, respectively. The WAXD image of the as-stretched PBT has two sharp peaks along the stretching direction and two broad peaks perpendicular to the stretching direction. The position of the sharp peak observed at $q=0.54 \AA^{-1}$ corresponds to $11.6 \AA$ and is assigned to the periodicity of the smectic phase..$^{5}$ The intensity of this peak decreases with increasing annealing temperature and eventually disappears (Figure 2). On the other hand, the two broad peaks on the equator first split vertically into four peaks (Figure 2b) and then into eight peaks (Figure 2d), and their intensities increase with increasing annealing 
Table 1 Sample histories of the PBT specimens for DSC measurements

\begin{tabular}{lll}
\hline DSC curve in Figure 3 & Stretching temperature & Thermal treatment \\
\hline A & Without stretching & None \\
B & Without stretching & $40^{\circ} \mathrm{C}, 30 \mathrm{~min}$ \\
C & Without stretching & $60^{\circ} \mathrm{C}, 30 \mathrm{~min}$ \\
D & $0^{\circ} \mathrm{C}$ & None \\
E & Room temperature & None \\
F & Room temperature & $40^{\circ} \mathrm{C}, 30 \mathrm{~min}$ \\
G & Room temperature & $60^{\circ} \mathrm{C}, 30 \mathrm{~min}$ \\
\hline
\end{tabular}

Abbreviations: DSC, differential scanning calorimetry; PBT, poly(butylene terephthalate).

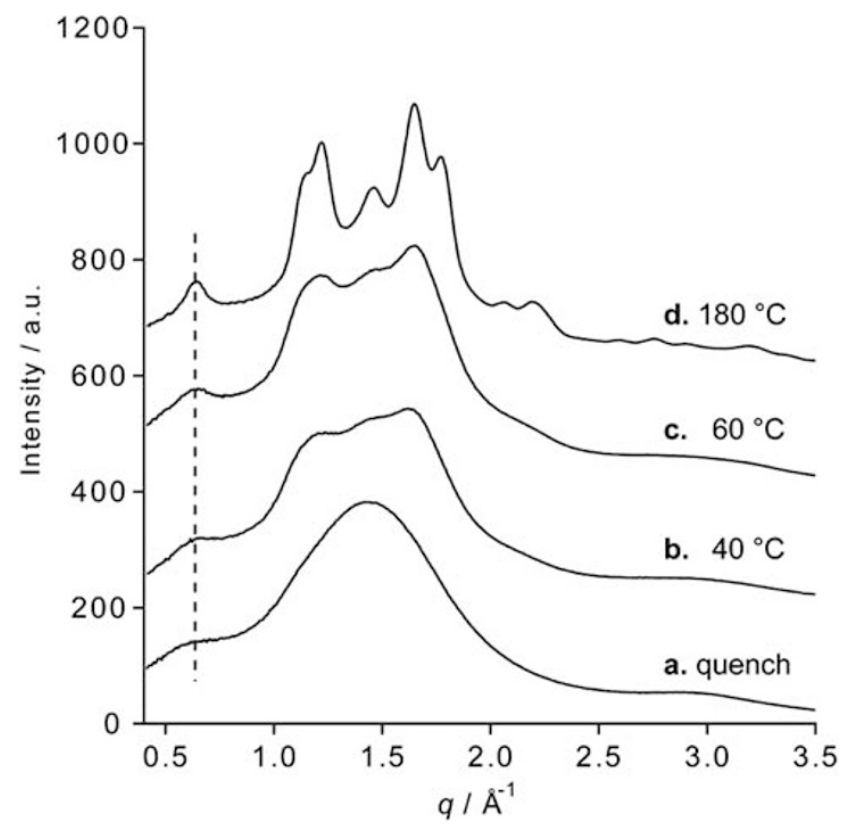

Figure 1 1D-WAXD patterns for quenched PBT (a) without stretching, and PBT annealed at (b) 40, (c) 60 and (d) $180^{\circ} \mathrm{C}$ after quenching. The curves for annealed PBT are shifted vertically for comparison. The vertical broken line represents the position of the (001) peak of the $\alpha$-form at $q=0.64 \AA^{-1}$.

temperature. The strong peaks are assigned to the $\alpha$-crystalline peaks. ${ }^{5}$ Results show that the smectic structure transforms into the $\alpha$-form on annealing of the stretched PBT. However, in Figure 1 , the $\alpha$-form peak at $q=0.64 \AA^{-1}$ is observed, but not the smectic peak at $q=0.54 \AA^{-1}$, which indicates that the smectic structure is formed only by stretching of the glass state PBT.

\section{Thermal properties of quenched PBT with and without stretching}

Figure 3a shows the DSC curves of PBT without stretching. The DSC curve for amorphous PBT in Figure 3a (curve A) has two endothermic peaks at 25 and $225^{\circ} \mathrm{C}$ and an exothermic peak at $40{ }^{\circ} \mathrm{C}$. The endothermic peak at $225^{\circ} \mathrm{C}$ is assigned to the melting temperature. For amorphous $\mathrm{PBT}$ annealed at 40 and $60^{\circ} \mathrm{C}$ (curves $\mathrm{B}$ and $\mathrm{C}$, respectively), the lower endothermic peak and the exothermic peak shift to the higher temperature region with increasing annealing temperature. The exothermic peak is due to crystallization. Cheng et al. ${ }^{17}$ have reported that the lower endothermic peak $\sim 10-15^{\circ} \mathrm{C}$ above the annealing temperature is due to melting. However, the DSC curves of amorphous PBT annealed at both 40 and $60^{\circ} \mathrm{C}$ have a small endothermic peak or shoulder at $31{ }^{\circ} \mathrm{C}$, which is independent of the annealing temperature. This small endothermic peak at $31{ }^{\circ} \mathrm{C}$ (onset $26^{\circ} \mathrm{C}$ ) is considered to be related to the $T_{\mathrm{g}}$ of amorphous PBT. When the DSC curve for amorphous PBT (curve A) around $T_{\mathrm{g}}$ is compared with the specific heat $C_{\mathrm{p}}$ data, ${ }^{15}$ the maximal value of the peak at $31{ }^{\circ} \mathrm{C}$ does not reach the expected value of liquid PBT shown by the broken line. ${ }^{15}$ The behavior of curve $\mathrm{A}$ around $T_{\mathrm{g}}$ indicates that amorphous PBT starts to crystallize during the change of $C_{\mathrm{p}}$ at $T_{\mathrm{g}}$ with an exotherm.

Figure $3 \mathrm{~b}$ shows DSC curves for the stretched PBT specimens. The curves for
PBT stretched at room temperature and those that annealed at 40 and $60^{\circ} \mathrm{C}$ after stretching at room temperature (Figure $3 b$, curves E, F and G, respectively) also have a peak at $31{ }^{\circ} \mathrm{C}$, the lower endothermic peak and the exothermic peak, and the melting peak. Figure $3 \mathrm{c}$ shows a comparison of the DSC curves for PBT with and without stretching. The peaks of PBT specimens that annealed at 40 and $60{ }^{\circ} \mathrm{C}$ with stretching (curves $\mathrm{F}$ and $\mathrm{G}$ ) are located at the same temperatures as those without stretching (curves B and C). In particular, the peak at $31{ }^{\circ} \mathrm{C}$ in all the DSC curves, which is considered to be related to the $T_{\mathrm{g}}$ of the amorphous liquid, does not shift by annealing. However, in the DSC curve of PBT stretched at $0{ }^{\circ} \mathrm{C}$ (Figure $3 \mathrm{~b}$, curve D), the lower endothermic peak, which is absent in the DSC curve of the quenched PBT without stretching (curve A), appears below $31{ }^{\circ} \mathrm{C}$. Figure $3 \mathrm{c}$ clearly shows the difference between the initial increases of curves $\mathrm{A}$ and $\mathrm{D}$ around $30^{\circ} \mathrm{C}$.

The exothermic peak at $40^{\circ} \mathrm{C}$ of the sample quenched and stretched at $0{ }^{\circ} \mathrm{C}$ (curve D) is smaller than that without stretching (curve A), whereas the effect of stretching on the exothermic behavior of samples annealed at $40{ }^{\circ} \mathrm{C}$ (curves $\mathrm{B}$ and $\mathrm{F}$ ) and $60^{\circ} \mathrm{C}$ (curves $\mathrm{C}$ and $\mathrm{G}$ ) is negligible. The annealed samples are semicrystalline, with a small fraction of the smectic structure in the stretched samples; therefore, the lower endothermic peak and the exothermic peak correspond to melting and recrystallization, respectively. The quenched sample is glassy (curve A) and the sample that stretched at $0{ }^{\circ} \mathrm{C}$ consists of the smectic structure and the amorphous phase; therefore, the difference in the exothermic peak indicates that the enthalpy of transition from the amorphous to the crystalline state is larger than that from the smectic to the crystalline structure.

\section{Relationship between smectic structure and glass transition}

Here, we consider the origin of the lowest peak at $25^{\circ} \mathrm{C}$ in the quenched PBT by stretching at $0{ }^{\circ} \mathrm{C}$. The quenched and stretched PBT has peaks at 25 and $31^{\circ} \mathrm{C}$, whereas the quenched $\mathrm{PBT}$ without stretching has only the peak at $31{ }^{\circ} \mathrm{C}$. According to WAXD results, the PBT stretched in the glass state has the smectic structure, and when quenched PBT with and without stretching is heated, the smectic structure and amorphous phase transform into the $\alpha$-form. The DSC curves of PBT that annealed at 40 and $60^{\circ} \mathrm{C}$, both with and without stretching, depend only on the annealing 


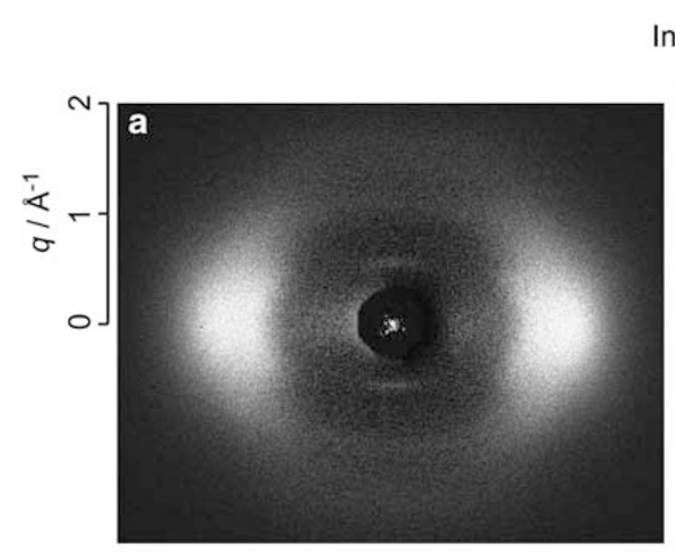

Intensity / a.u.

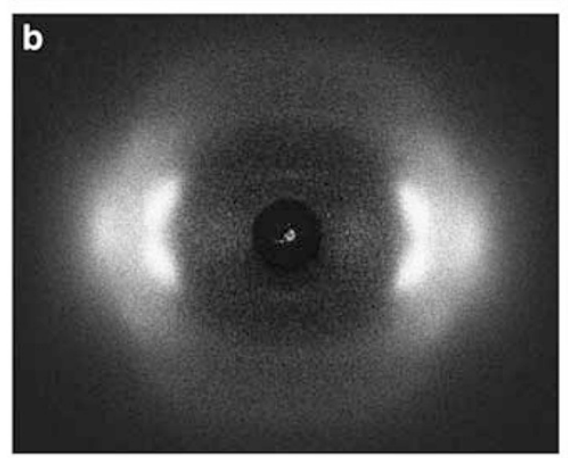

$0 \quad 100$

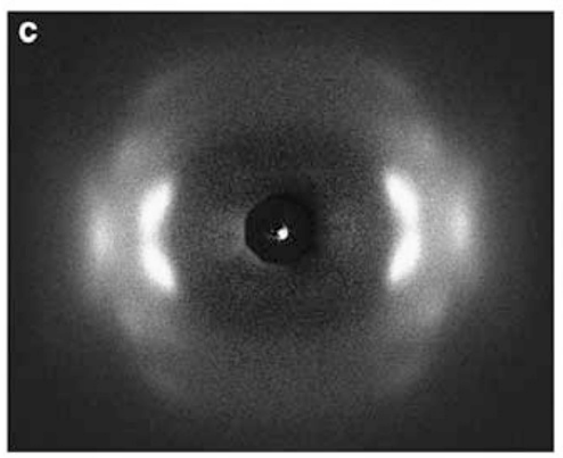

d

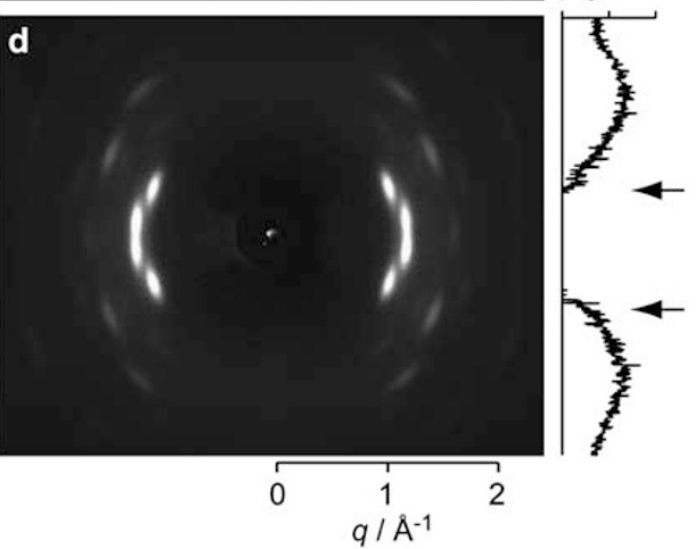

Figure 2 2D-WAXD images of (a) PBT stretched at room temperature after quenching, and the stretched PBT annealed at (b) 40 , (c) 60 and (d) $180^{\circ} \mathrm{C}$. The patterns on the right side of the 2D-WAXD images are the intensities in the meridional direction. The arrows in the right figures represent the position of the smectic peak at $q=0.54 \AA^{-1}$.

temperature, regardless of stretching, and exhibit the $31^{\circ} \mathrm{C}$ peak. The result indicates that the oriented amorphous PBT also has enthalpy relaxation at $31^{\circ} \mathrm{C}$. The lowest peak at $25^{\circ} \mathrm{C}$ is present only in the DSC curve of the quenched PBT by stretching at $0{ }^{\circ} \mathrm{C}$, which has the smectic structure. Therefore, we propose that the lowest peak at $25^{\circ} \mathrm{C}$ (onset $21^{\circ} \mathrm{C}$ ) for PBT that stretched at $0{ }^{\circ} \mathrm{C}$ is the $T_{\mathrm{g}}$ of the smectic structure formed by the stretching of amorphous PBT, and that the $T_{\mathrm{g}}$ of the smectic structure $T_{\mathrm{g}}^{\mathrm{sm}}$ and that of the isotropic or oriented amorphous liquid $T_{\mathrm{g}}$ am are 21 and $26^{\circ} \mathrm{C}$, respectively, according to the onset temperatures of the endothermic peak.

We now discuss the reason for the disappearance of $T_{\mathrm{g}}^{\mathrm{sm}}$ in the stretched and annealed PBT specimens (Figure 3, curve F and $G$ ), in which the smectic structure is still evident from the WAXD result (Figure 2). The WAXD images in Figure 2 show that the smectic structure transforms into the $\alpha$-form during the annealing process. Therefore, a continuous decrease in the fraction of the smectic structure is the main cause for the disappearance of the $T_{\mathrm{g}}^{\mathrm{sm}}$ endothermic peak in Figure 3. Furthermore, there is a possibility that stabilization of a part of the smectic structure by crystallization confines the mobility of the PBT chains and thus increases $T_{\mathrm{g}}^{\mathrm{sm}}$.

From the results of this study, we have confirmed that the smectic structure is formed only by the stretching of amorphous PBT, and determined that PBT has two $T_{\mathrm{g}}$ values: $T_{\mathrm{g}}^{\mathrm{sm}}$ at $21^{\circ} \mathrm{C}$ and $T_{\mathrm{g}}^{\mathrm{am}}$ at $26^{\circ} \mathrm{C}$. Multiple- $T_{\mathrm{g}}$ behavior has been reported for some liquid crystalline polymers, ${ }^{18-20}$ in addition to crystalline polymers. ${ }^{10,12}$ Some liquid crystalline polymers are reported to have $T_{\mathrm{g}}$ sm below $T_{\mathrm{g}}{ }^{18-20} \mathrm{PBN}$ and $\mathrm{iPP}$, in which $T_{\mathrm{g}}^{\mathrm{sm}}$ is above $T_{\mathrm{g}} \mathrm{am}$, form the smectic structure without stretching. In these polymers, the fraction of smectic structure, rather than the crystalline phase, increases at temperatures between $T_{\mathrm{g}}^{\mathrm{sm}}$ and $T_{\mathrm{g}}^{\mathrm{am} \cdot 10,12}$ Chen and Zachmann ${ }^{18}$ reported the locations of $T_{\mathrm{g}}$ for a liquid crystalline structure, $T_{\mathrm{g}}^{\mathrm{LC}}$, and an isotropic phase $T_{\mathrm{g}}$ iso with respect to the free volume theory. According to their interpretation, $T_{\mathrm{g}}^{\mathrm{LC}}$ should be lower (higher) than $T_{\mathrm{g}}$ iso when the difference between the volumes at $T_{\mathrm{g}}^{\mathrm{LC}}$ and $T_{\mathrm{g}}$ iso is larger (smaller) than the volume change on liquid crystallization. We propose the following relationship between smectic structure formation and $T_{\mathrm{g}}$. A material with $T_{\mathrm{g}}^{\mathrm{sm}}$ higher than $T_{\mathrm{g}}$ am forms the smectic structure by simple quenching or annealing above $T_{\mathrm{g}}^{\mathrm{am}}$. On the other hand, a material with $T_{\mathrm{g}}$ sm lower than $T_{\mathrm{g}}$ am forms the smectic structure only by stretching of the glassy state. In the case of PBT, the smectic structure is formed only by stretching of the glassy state, because $T_{\mathrm{g}}{ }^{\mathrm{sm}}$ is lower than $T_{\mathrm{g}}$ am . Similar relationships are expected for poly (ethylene terephthalate) ${ }^{7,8}$ and poly(ethylene naphthalate). ${ }^{9}$ 

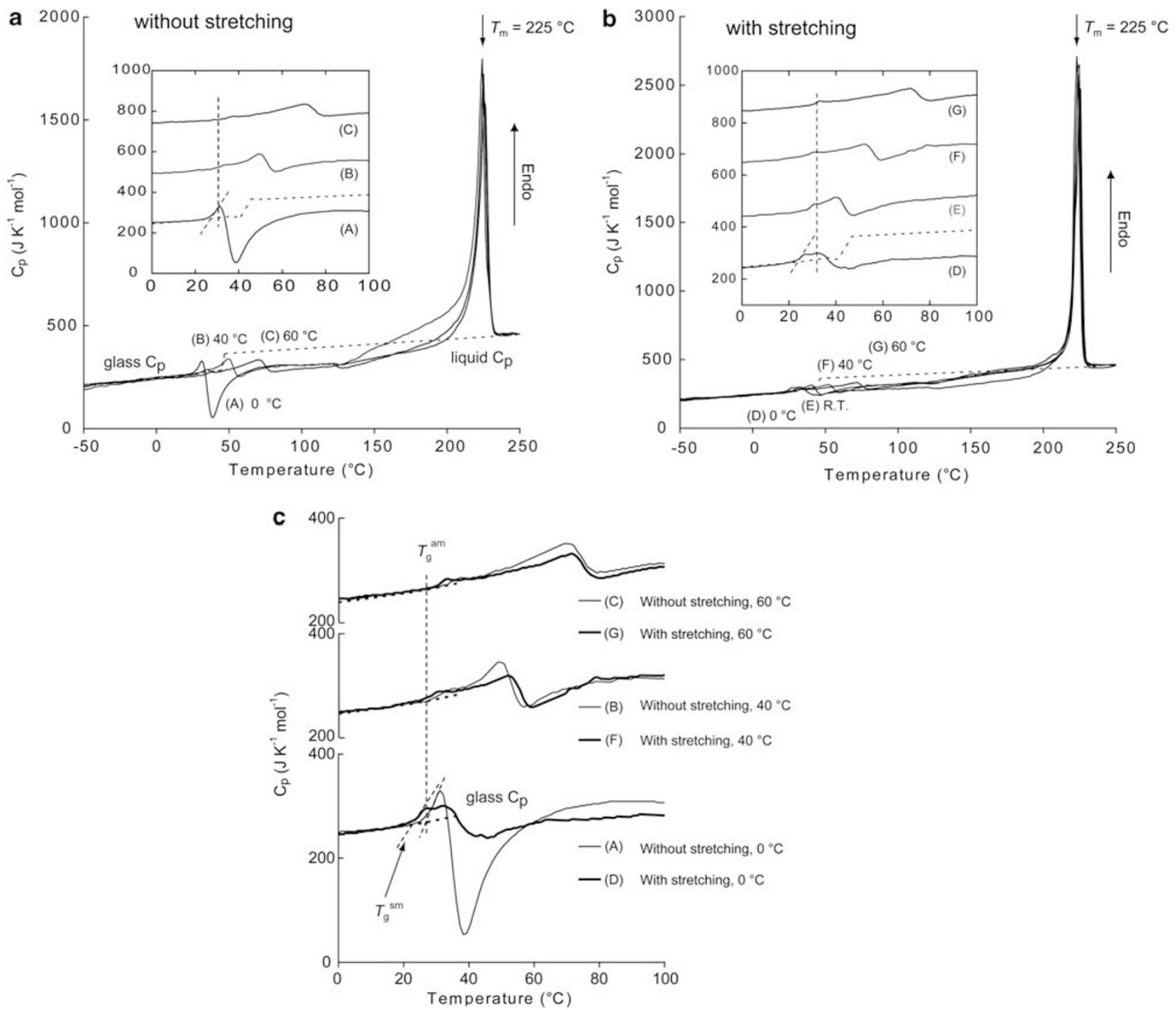

Figure 3 DSC curves for the heating of PBT with and without stretching. (a) PBT quenched to (A) $0^{\circ} \mathrm{C}$ without stretching and annealed at (B) 40 and (C) $60^{\circ} \mathrm{C}$ after quenching. (b) Quenched PBT stretched at (D) $0^{\circ} \mathrm{C}$ and (E) at room temperature, and annealed at (F) 40 and (G) $60^{\circ} \mathrm{C}$ after stretching at room temperature. (c) Comparison of the DSC curves for (a) PBT without stretching (thin lines) and (b) PBT with stretching (thick lines) in the range from 0 to $100{ }^{\circ} \mathrm{C}$. The inserts in (a) and (b) are enlarged curves for the range between 0 and $100^{\circ} \mathrm{C}$, which have been shifted vertically. The dotted lines in a-c indicate the specific heat capacity of the liquid and glass states of PBT from Konishi et al. ${ }^{14}$

\section{CONCLUSION}

The smectic structure is observed in quenched PBT only by stretching. The stretched PBT has $T_{\mathrm{g}}$ at $21^{\circ} \mathrm{C}$, in addition to the $T_{\mathrm{g}}$ of the amorphous liquid $T_{\mathrm{g}}^{\mathrm{am}}$ at $25^{\circ} \mathrm{C}$. We propose that the $T_{\mathrm{g}}$ at $21{ }^{\circ} \mathrm{C}$ for PBT is the $T_{\mathrm{g}}$ of the smectic structure $T_{\mathrm{g}}^{\mathrm{sm}}$. $T_{\mathrm{g}}^{\mathrm{sm}}$ is located below $T_{\mathrm{g}}^{\mathrm{am}}$ in PBT; therefore, the smectic structure is formed only by stretching after quenching.

\section{ACKNOWLEDGEMENTS}

This work was partly supported by KAKENHI (Grant-in-Aid for Scientific Research) from the Ministry of Education, Culture, Sports, Science and Technology of Japan.
Takashi Konishi and Yoshihisa Miyamoto Department of Interdisciplinary Environment, Graduate School of Human and Environmental Studies, Kyoto University, Kyoto, Japan E-mail: t.konishi@kt5.ecs.kyoto-u.ac.jp

1 Mencik, Z. The crystal structure of poly(tetramethylene terephthalate). J. Polym. Sci. Polym. Phys. Ed. 13, 2173-2181 (1975).

2 Jakeways, R., Ward, I. M., Wilding, M. A., Hall, I. H., Desborough, I. J. \& Pass, M. G. Crystal deformation in aromatic polyesters. J. Polym. Sci. Polym. Phys. Ed. 13, 799-813 (1975).

3 Yokouchi, M., Sakakibara, Y., Chatani, Y., Tadokoro, H., Tanaka, T. \& Yoda, K. Structures of two crystalline forms of poly(butylene terephthalate) and reversible transi- tion between them by mechanical deformation. Macromolecules 9, 266-273 (1976).

4 Hall, I. H. \& Pass, M. G. Chain conformation of poly(tetramethylene terephthalate) and its change with strain. Polymer 17, 807-816 (1976).

5 Song, K. Formation of polymorphic structure and its influences on properties in uniaxially stretched polybutylene terephthalate films. J. Appl. Polym. Sci. 78, 412-423 (2000)

6 Konishi, T. \& Miyamoto, Y. Crystallization of poly(butylene terephthalate) from the glass. Macromolecules 43, 375-383 (2010)

7 Bonart, R. Parakristalline strukturen in polyäthyleneterephthalat (PET). Kolloid-Z. 213, 1-11 (1966).

8 Fukao, K., Koyama, A., Tahara, D., Kozono, Y., Miyamoto, Y. \& Tsurutani, N. Structure formation from the oriented glassy states of poly(ethylene terephthalate). J. Macromol. Sci. B. 42, 717-731 (2003).

9 Jakeways, R., Klein, J. L. \& Ward, I. M. The existence of a mesophase in poly(ethylene naphthalate). Polymer 37, 3761-3762 (1996). 
10 Konishi, T., Nishida, K., Matsuba, G. \& : Kanaya, T. Mesomorphic phase of poly(butylene-2,6-naphthalate). Macromolecules 41, 3157-3161 (2008).

11 Natta, G. \& Corradini, P. Structure and properties of isotactic polypropylene. Nuovo. Cimento. (Suppl.) 15, 40-51 (1960).

12 Miyamoto, Y., Fukao, K., Yoshida, T., Tsurutani, N. \& Miyaji, H. Structure formation of isotactic polypropylene from the glass. J. Phys. Soc. Jpn. 69, 1735-1740 (2000).

13 Minami, S., Tsurutani, N., Miyaji, H., Fukao, K. \& Miyamoto, Y. SAXS study on structure formation from the uniaxially oriented glass in isotactic polypropylene. Polymer 45, 1413-1416 (2004).

14 Konishi, T., Nishida, K., Kanaya, T. \& Kaji, K. Effect of isotacticity on formation of mesomorphic phase of isotactic polypropylene. Macromolecules $\mathbf{3 8}$, 8749-8754 (2005).

15 Pyda, M., Nowak-Pyda, E., Mays, J. \& Wunderlich, B. Heat Capacity of Poly(butylene terephthalate). J. Polym. Sci. Part B Polym. Phys. 42, 4401-4411 (2004).

16 Pyda, M., Nowak-Pyda, E., Heeg, J., Huth, H., Minakov, A. A., Di Lorenzo, M. L., Schick, C. \& Wunderlich, B. Melting and crystallization of poly(butylene terephthalate) by temperature-modulated and superfast calorimetry. J. Polym. Sci. Part B Polym. Phys. 44, 1364 1377 (2006).

17 Cheng, S. Z. D., Pan, R. \& Wunderlich, B. Thermal analysis of poly(butylene terephthalate) for heat capacity, rigid-amorphous content, and transition behavior. Macromol. Chem. 189, 2443-2458 (1988).
18 Chen, D. \& Zachmann, H. G. Glass-transition temperature of copolyesters of PET, PEN and PHB as determined by dynamic mechanical analysis. Polymer 32, 1612-1621 (1991)

19 del Campo, A., Bello, A., Perez, E., Garcia-Bernabe, A. \& Diaz Calleja, R. Amorphous-smectic glassy mainchain LCPs, 1-Poly(ether esters) derived from hydroxybibenzoic acid and (R,S)- and (R)-2-methylpropane1,3-diol. Macromol. Chem. Phys. 203, 2508-2515 (2002).

20 Tokita, M., Funaoka, S. \& Watanabe, J. Study on smectic liquid crystal glass and isotropic liquid glass formed by thermotropic main-chain liquid crystal polyester. Macromolecules 37, 9916-9921 (2004). 